\title{
Diagnosis, Treatment and Clinical Features of Cutaneous Leishmaniasis in Saudi Arabia
}

\author{
Yousry A. Hawash ${ }^{1,2, *}$, Khadiga A. Ismail ${ }^{1,3}$, Maha M. Abdel-Wahab", Mahmoud Khalifa ${ }^{5}$ \\ ${ }^{1}$ Laboratory Medicine Department, Faculty of Applied Medical Sciences, Taif University, Taif, Saudi Arabia; ${ }^{2}$ Parasitology Department, National Liver \\ Institute, Menoufia University, Menoufia, Egypt; ${ }^{3}$ Parasitology Department, Faculty of Medicine, Ain-Shams University, Cairo, Egypt; ${ }^{4}$ Parasitology \\ Department, Research Institute of Ophthalmology, Giza, Egypt; ${ }^{5}$ Dermatology Department, King Faisal General Hospital, Taif, Saudi Arabia
}

\begin{abstract}
Cutaneous leishmaniasis (CL) has been one of the most common parasitic diseases in Saudi Arabia. This study exhibits the clinical features, diagnosis, cytokine profile and treatment of CL patients in Al-Taif province. Ninety CL suspects at a tertiary care general hospital were enrolled in one-year study. Patients were interviewed, clinically-examined, and subjected to laboratory tests: skin scraping smear microscopy, OligoC-TesT commercial PCR (Coris BioConcept) and kinetoplast DNA (kDNA) PCR for Leishmania diagnosis. Interferon-gamma (RayBio; Human IFN- $\gamma$ ) and nitric oxide (NO) levels in patients' sera were evaluated before treatment with sodium stibogluconate (pentostam) with 20-day intramuscular drug regimen. Positive rates of microscopy, commercial PCR and kDNA PCR were $74.4 \%, 95.5 \%$ and $100 \%$, respectively. Patients came to hospital mostly in winter (45.0\%). CL was frequently exhibited in Saudi patients (78.8\%), male gender $(70.7 \%)$, age $<20$ years $(50.0 \%)$, rural-dwellers $(75.5 \%)$ and patients with travel history $(86.6 \%)$. Lesion was mostly single ulcer (93.3\%), occurred in the face (67.7\%). Upon pentostam treatment, $85.1 \%$ of ulcers showed rapid healing signs. Levels of IFN- $\gamma$ and NO were significantly higher in the healing than the non-healing cases $(P<0.001)$. The kDNA PCR proved more sensitive than microscopy and OligoC-TesT commercial PCR. Our results open perspectives for IFN- $\gamma$ use as a biomarker predicting treatment response.
\end{abstract}

Key words: Cutaneous leishmaniasis, clinical feature, PCR diagnosis, cytokine profile

\section{INTRODUCTION}

Cutaneous leishmaniasis (CL) is a vector-borne protozoan infection affecting a large number of people in several countries [1]. Around 1.5 million CL new cases are emerging annually and approximately 350 million people are at risk [2]. The great number of CL cases occurs in Algeria, Brazil, Afghanistan, Iran, Peru, Syria and Saudi Arabia. The disease is often asymptomatic, but it can exhibit symptoms very similar to that of many other skin diseases [3].

The progress of $\mathrm{CL}$ and its clinical outcomes are strongly-influenced by the host immune response mounted towards the causative parasite [4]. Interferon gamma (IFN- $\gamma$ ) is a major cytokine involved in macrophage activation. Upon activation,

\footnotetext{
- Received 1 February 2018, revised 6 April 2018, accepted 24 April 2018.

*Corresponding author (yousryhawash@gmail.com)

(C) 2018, Korean Society for Parasitology and Tropical Medicine

This is an Open Access article distributed under the terms of the Creative Commons

Attribution Non-Commercial License (http://creativecommons.org/licenses/by-nc/4.0)

which permits unrestricted non-commercial use, distribution, and reproduction in any

medium, provided the original work is properly cited.
}

the macrophages produce nitric oxide (NO), a potent mediator involved in intracellular and extracellular Leishmania killing [5].

Diagnosis of $\mathrm{CL}$ is usually done through demonstration of the leishmanial parasite in skin smears or biopsy with direct microscopy-based detection methods that commonly lack sensitivity and specificity [6]. Several PCR-based assays that allow both parasite detection and species identification, with a high degree of sensitivity and specificity, have been developed [7].

CL skin lesions are often self-healing, but sometimes mandate treatment. The pentavalent antimonial medications remain the standard treatment in many parts in the world [8]. Nonetheless, these compounds are frequently blamed for their serious side-effects and the reported possibility of treatmentfailure, resistance and skin lesions relapse [9].

In this study, we presented a comprehensive report describing the clinical features, diagnosis, cytokine profile and the antimonial treatment's response of CL using cases with suspected leishmanial lesions from Al-Taif province, western Saudi Arabia. 


\section{MATERIALS AND METHODS}

\section{Setting and population}

This descriptive study was carried out in Al-Taif region, an area of 13,840 km², situated west Saudi Arabia (Fig. 1). The climate in this high altitude region is variable and the rain usually falls in late summer and autumn seasons. This study was conducted on 90 patients with active skin lesion(s) suspicious for CL. Cases were selected from those patients presented to the Dermatology department at King Feisal, a referral tertiary level general hospital in Taif during the period between September 2016 and August 2017. CL patients with history of prior therapy to the skin lesion(s), who had co-morbid diseases like cancer, chronic renal or liver diseases or infections as viral hepatitis or human immunodeficiency virus, was excluded from participation in the study.

\section{Ethical considerations}

An approval of Institutional Review Board (IRB) at Al-Taif University and King Feisal General Hospital (RAC \#207004) was declared before the initiation of the study. In addition, a written informed consent was obtained from each participant after a detailed explanation of the study's purpose, procedures, potential risks and benefits.

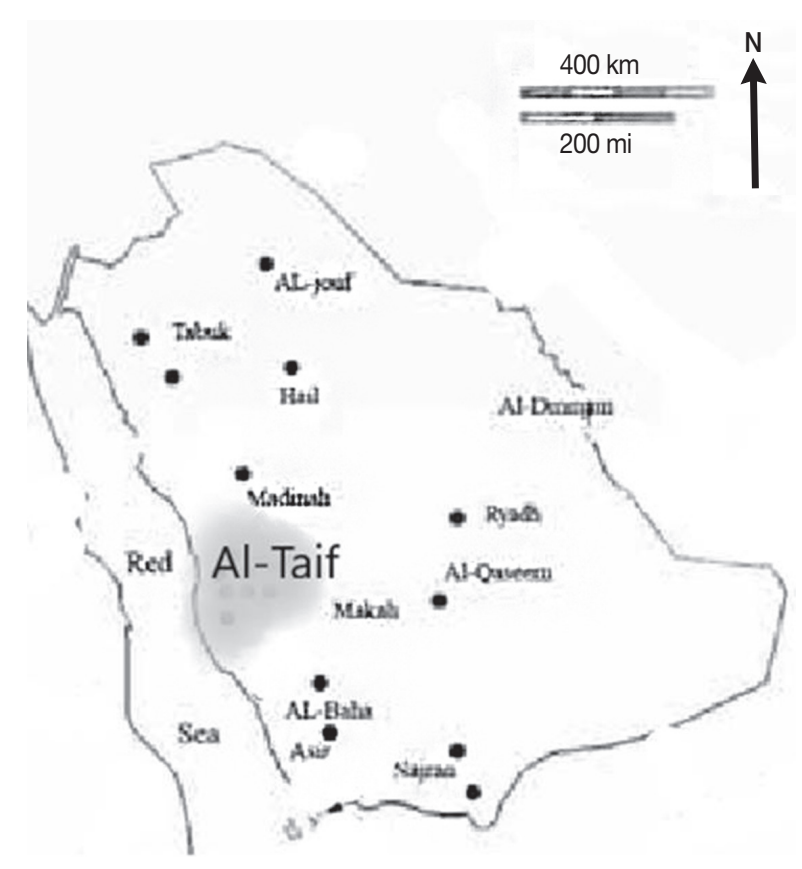

Fig. 1. Map of Al-Taif region in Saudi Arabia.

\section{Clinical examination}

Patients were interviewed with structured questionnaire and clinically-examined by a specialized dermatologist. The questionnaire comprised, in its first part, information about the patient's socio-demographic features (age, gender, residence, nationality, animals in or near the house and leishmaniasisendemic areas visited 1-3 months before eruption of the skin lesions) and in its second part, information about the patient's medical history (prior medications, home remedies, concomitant diseases and lesion's evolution time). The lesion's evolution time was calculated by the time interval from the lesion's eruption day till the patient's consultation day.

The clinical examination involved tissue-affected, lesion characteristics (number, size, site and appearance). The lesion's size was measured through 2 crossing diameters by a metric caliper. For patients with multiple lesions, the surface area was reported as a mean size of the total lesions.

\section{Microscopic examination for Leishmania}

Scraping materials were taken from the patient's lesion and divided into 2 parts: one part was directly used for microscopic examination and another part was stored at $4^{\circ} \mathrm{C}$ for subsequent molecular parasitological diagnosis. Tissues were scraped from the active edge of the lesion by using a sterile lancet. The scraped material was smeared on a slide glass, fixed with one drop of methanol, stained with Giemsa stain and examined under a light microscope for leishmanial amastigotes, as previously described [10].

\section{Molecular detection of Leishmania}

Nnucleic acid of the stored scraping materials were extracted and purified using a genomic DNA purification Kit (Ferments, UK) according to manufacturer's protocol. DNA was eluted with $50 \mu$ lelution buffer and kept at $-20^{\circ} \mathrm{C}$ until PCR analysis. The first PCR analysis was done using Leishmania OligoC-TesT commercial kit (Coris Bioconcept, Gembloux, Belgium). The second PCR was kinetoplast DNA (kDNA) PCR, an in-house semi-nested conventional PCR. Amplification reaction and products analysis were performed with reference to a previous protocol [11].

\section{Assay on IFN- $\gamma$ and NO in sera}

All participants were asked to give blood sample for assays on IFN- $\gamma$ and NO levels in their sera before treatment. After overnight fasting, $5 \mathrm{ml}$ of venous blood were withdrawn, kept 
at room temperature for $30 \mathrm{~min}$. Serum was transferred to sterile tubes, centrifuged at 3,000 rpm for $10 \mathrm{~min}$ at $4^{\circ} \mathrm{C}$ and kept at $-20^{\circ} \mathrm{C}$. Level of IFN- $\gamma$ was determined using RayBio ${ }^{\circledR}$ Human ELISA commercial kit (Norcross, Georgia, USA) following the manufacturer's protocol.

Serum nitrate concentration, as a stable end-product of nitric oxide, was measured by an endpoint one-step enzymatic assay using nitrate reductase. The concomitant reduction of nitrate to nitrite by NADPH was monitored by the oxidation of the coenzyme and the decrease in absorbance at $340 \mathrm{~nm}(\mu \mathrm{mol} / \mathrm{L})$.

\section{Patients treatment and follow-up}

Patients eligible for treatment were selected and sodium stibogluconate (Pentostam, GlaxoSmithKline, Uxbridge, UK) was administered intramuscularly at a dose of $20 \mathrm{mg} / \mathrm{kg} /$ day for 20 days. Ulcerative lesions were observed for healing during the intramuscular injections. Resolution signs of the lesions included inflammatory signs (skin erythema, edema and hardening) and size regression (partial or complete scarring, re-epithelialization).

\section{Statistical analysis}

Collected data were coded, tabulated and statistically analyzed using SPSS 19 program (SPSS, Chicago, Illinois, USA). Descriptive data were analyzed as frequency, percentage, and mean \pm standard deviation (SD). Serum level of IFN- $\gamma$ was expressed as non-parametric variable and compared between groups using Mann-Whitney to test significant difference at $P<0.05$.

\section{RESULTS}

\section{Socio-epidemiological features}

Ninety CL suspects were identified and investigated in our study, with an estimated average annual frequency rate of 7.5 cases per 100,000 inhabitants. Cases registered all the year around, majority of cases were recorded in winter $(45.0 \%)$, reached a peak at February/March (16.6\%) and March/April (13.3\%) interval periods. The cases decreased in other months and minimum in August (3.3\%) and November (4.4\%) (Fig. 2).

Of all CL patients, investigated, $77.7 \%$ were male (mean age $=28.40 \pm 21.08$ ) and $22 \%$ female (mean age $42.5 \pm 21.28$ ). Patients were recruited into 4 age groups and their demographic characteristics were described in relation to their age groups (Table 1). Majority of cases were below 20 years (50.0\%), coming from remote rural areas (75.5\%) and had a travel history to leishmania-endemic areas inside or outside the country (86.6\%). Significant difference was not observed in these 3 variables between the patients' age groups $(P>0.05$, chi-square).

Infection appeared more frequently in Saudi people (71; $78.8 \%$ ) than in non-Saudi $(21.1 \%)$, with high significant differences observed among age groups and patient's nationality $(P<0.001)$. Moreover, $68.8 \%$ cases reported contact with domestic animals like dogs, sheep, goats, cattle, buffaloes, donkey or chickens in or nearby their houses, significant difference observed between different age groups $(P<0.05)$.

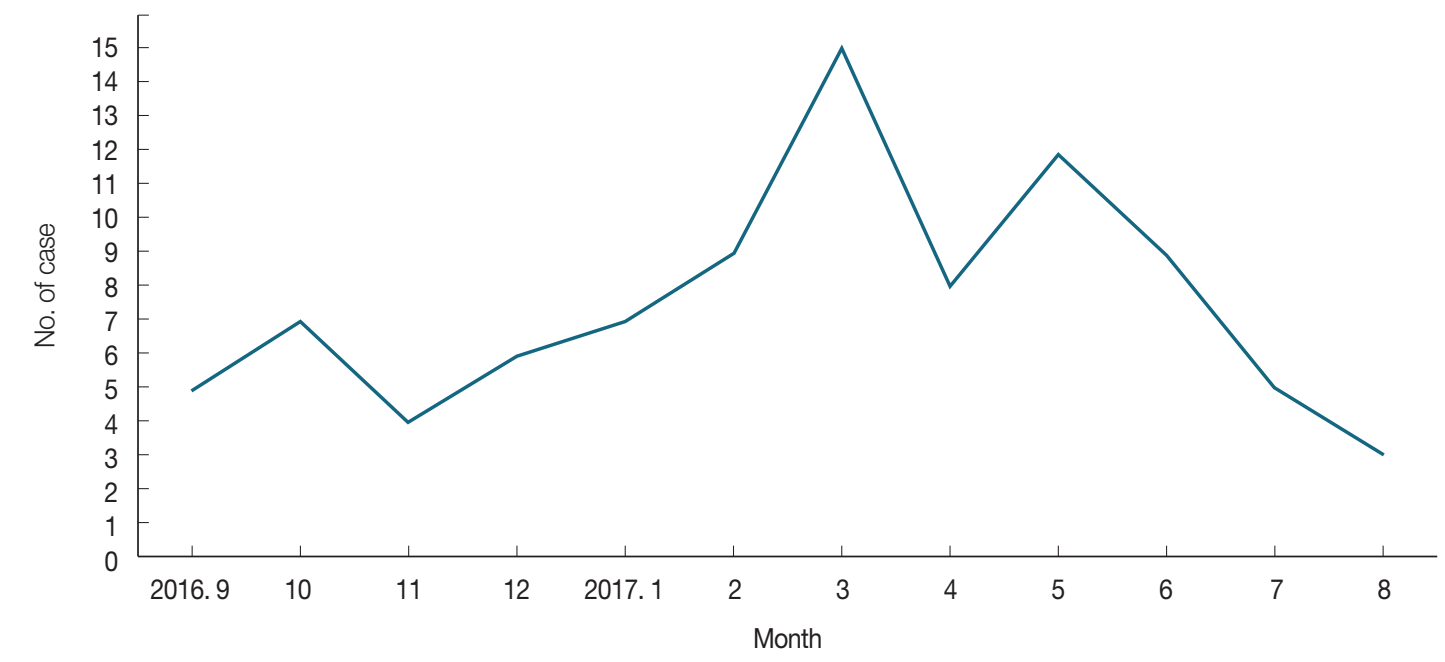

Fig. 2. A month-wise distribution of 90 leishmanial cases enrolled in this study. 


\section{Clinical characteristics}

Considering the leishmanial lesions, examined, all were confined to the patients' skin with no mucosal tissue involvement noticed. The mean number of lesions was $1.08 \pm 0.356$ (mean \pm SD) and the mean surface area of $6.35 \pm 3.01 \mathrm{~cm}^{2}$. The lesion's evolution time ranged between 3 and 15 months (mean $\pm \mathrm{SD}=5.96 \pm 2.53$ ). The majority of lesions were of 3-6 months durations (85.5\%). Most of the patients (84; 93.3\%)

Table 1. Demographic features of $90 \mathrm{CL}$ suspects by age group

\begin{tabular}{|c|c|c|c|c|c|}
\hline \multirow{2}{*}{ Variable (No.) } & \multicolumn{4}{|c|}{ Number of age group (\%) } & \multirow{2}{*}{$P$-value } \\
\hline & $5-19 y r$ & $20-39 y r$ & $40-59 \mathrm{yr}$ & $\geq 60 \mathrm{yr}$ & \\
\hline \multicolumn{6}{|l|}{ Gender } \\
\hline Male (70) & $39(43.3)$ & $10(11.1)$ & $12(13.3)$ & $9(10)$ & 0.090533 \\
\hline Female (20) & $6(6.6)$ & $2(2.2)$ & $8(8.8)$ & $4(4.4)$ & \\
\hline \multicolumn{6}{|l|}{ Residence } \\
\hline Rural (68) & $37(41.1)$ & $10(11.1)$ & $12(13.3)$ & $9(10)$ & 0.22345 \\
\hline Urban (22) & $8(8.8)$ & $2(2.2)$ & $8(8.8)$ & $4(4.4)$ & \\
\hline \multicolumn{6}{|l|}{ Nationality } \\
\hline Saudi (71) & $42(46.6)$ & $9(10)$ & $9(10)$ & $11(12.2)$ & $0.000187^{\star \star}$ \\
\hline Non-Saudi (19) & $3(3.3)$ & $3(3.3)$ & 11 (12.2) & $2(2.2)$ & \\
\hline \multicolumn{6}{|l|}{ Travel history } \\
\hline Yes (78) & 35 (38.8) & $11(12.2)$ & $19(21.1)$ & $13(14.4)$ & 0.21331 \\
\hline No (12) & $10(11.1)$ & $1(1.1)$ & $1(1.1)$ & $0(0.0)$ & \\
\hline \multicolumn{6}{|c|}{ Animals around house } \\
\hline Yes (62) & $36(40)$ & $7(7.7)$ & $9(10)$ & $10(11.1)$ & $0.030195^{\star}$ \\
\hline No (28) & $9(10)$ & $5(5.5)$ & $11(12.2)$ & $3(3.3)$ & \\
\hline
\end{tabular}

${ }^{* *}$ Highly significant $(P<0.001)$; ${ }^{*}$ Significant $(P<0.05)$.

Table 2. Clinical features of $C L$ active skin lesions by age group

\begin{tabular}{|c|c|c|c|c|c|}
\hline \multirow{2}{*}{ Lesion (patient no.) } & \multicolumn{4}{|c|}{ Case number (\%) of age group } & \multirow{2}{*}{$P$-value } \\
\hline & $5-19 y r$ & $20-39 \mathrm{yr}$ & $40-59 \mathrm{yr}$ & $\geq 60 \mathrm{yr}$ & \\
\hline \multicolumn{6}{|l|}{ Type } \\
\hline Nodular (5) & $2(2.2)$ & $1(1.1)$ & $2(2.2)$ & $0(0.0)$ & 0.851897 \\
\hline Ulcerative (85) & $43(47.7)$ & $11(12.2)$ & $18(20)$ & $13(14.4)$ & \\
\hline \multicolumn{6}{|l|}{ Ulcer } \\
\hline Wet (12) & $5(5.5)$ & $3(3.3)$ & $3(3.3)$ & $1(1.1)$ & 0.506986 \\
\hline Dry (73) & $38(42.2)$ & $8(8.8)$ & $15(16.6)$ & $12(13.3)$ & \\
\hline \multicolumn{6}{|l|}{ Duration } \\
\hline$<6$ months $(77)$ & $39(43.3)$ & $9(9.9)$ & $19(21.1)$ & $10(11.1)$ & 0.568424 \\
\hline 6-12 months (9) & $5(5.5)$ & $2(2.2)$ & $1(1.1)$ & $1(1.1)$ & \\
\hline >12 months (4) & $1(1.1)$ & $1(1.1)$ & $0(0.0)$ & $2(2.2)$ & \\
\hline \multicolumn{6}{|l|}{ Location } \\
\hline Face (61) & $38(42.2)$ & $6(6.6)$ & $8(8.8)$ & $9(9.9)$ & $0.000273^{*}$ \\
\hline Upper limbs (15) & $4(4.4)$ & $5(5.5)$ & $3(3.3)$ & $3(3.3)$ & \\
\hline Lower limbs (14) & $3(3.3)$ & $1(1.1)$ & $9(9.9)$ & $1(1.1)$ & \\
\hline \multicolumn{6}{|l|}{ Number } \\
\hline Single (84) & $43(47.7)$ & $11(12.2)$ & $19(21.1)$ & $11(12.2)$ & 0.722736 \\
\hline Double (4) & $1(1.1)$ & $1(1.1)$ & $1(1.1)$ & $1(1.1)$ & \\
\hline Multiple (2) & $1(1.1)$ & $0(0.0)$ & $0(0.0)$ & $1(1.1)$ & \\
\hline \multicolumn{6}{|l|}{ Surface area } \\
\hline $1-5 \mathrm{~cm}(35)$ & $16(17.7)$ & $4(4.4)$ & $7(7.7)$ & $8(8.8)$ & 0.224655 \\
\hline $5-10 \mathrm{~cm}(54)$ & 29 (32.2) & $8(8.8)$ & $13(14.4)$ & $4(4.4)$ & \\
\hline$>10 \mathrm{~cm}(1)$ & $0(0.0)$ & $0(0.0)$ & $0(0.0)$ & $1(1.1)$ & \\
\hline
\end{tabular}

*Highly significant $(P<0.001)$. 
presented with single lesion, while 6 patients developed 2-3 lesions. The highest proportion of lesions $(85 ; 94.4 \%)$ was of ulcerative type while $5.5 \%$ of lesions were nodular. Lesions affected exposed body parts, mainly the face $(61 ; 67.7 \%)$, followed by the upper limbs $(15 ; 16.6 \%)$ and the lower limbs (14; 15.5\%). Table 2 shows the clinical features of the leishmanial skin lesions relative the different age groups. The mean surface areas of lesions were below $5 \mathrm{~cm}$ in 35 (38.8\%) of cases, $5-10 \mathrm{~cm}$ in $54(60 \%)$ patients and more than $10 \mathrm{~cm}$ in just one case. The ulcerative lesions looked dry with scales in $85.8 \%$ (73/85) and wet in $14.1 \%$ (12/85) of cases. The lesions were exclusively-found on exposed body areas: the face in $67.7 \%$, the lower limbs in $15.5 \%$ ) and the upper limbs in $16.6 \%$ of patients. The facial lesions were found frequent in young patients below 19 years $(38 / 61 ; 62.2 \%)$, while the limbs lesions were described more in older ages $(\approx 86 \%)$, with highly significant differences observed among the patients age groups ( $P=0.000273$, chi-square).

\section{Diagnostic tests results}

The Leishmania amastigote forms were exhibited in 67 (74.4\%) cases by Giemsa stained smear microscopy. In com-

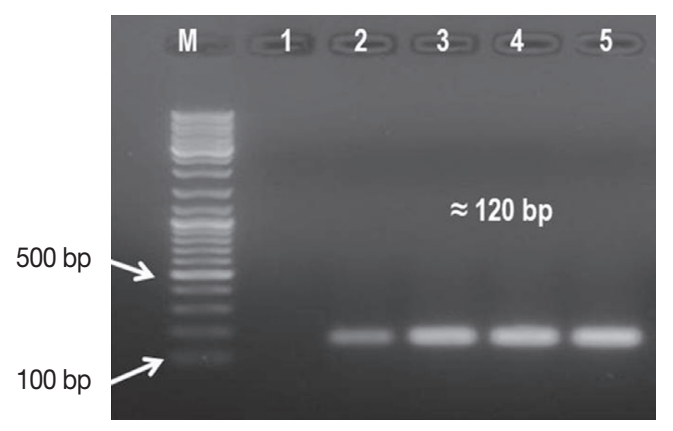

Fig. 3. An ethidium bromide-stained $1.5 \%$ agarose gel of kDNA semi-nested PCR. Lane 1, negative sample; lanes 2-5, amplification product ( $\approx 120$ bp) of Leishmania spp. M, 100 bp DNA marker. parison, the leishmanial DNA was identified in 86 (95.5\%) cases with the OligoC-TesT. The assay picked $19 \mathrm{CL}$ cases more than microscopy. The semi-nested kDNA PCR assay identified the remaining 4 CL cases, achieving 100\% sensitivity (Fig. 3). Importantly, all leishmanial cases identified by microscopy were also positives for the parasite DNA.

\section{Treatment and follow up results}

Forty-seven (52.2\%) patients were found suitable for treatment with sodium stibogluconate. All patients were followedup at the end of therapy. Forty patients (85.1\%) displayed clinical signs for partial or complete resolution of their skin lesions. For IFN- $\gamma$ and NO serum levels analysis, these patients were allocated as group (A). The remaining patients $(n=7)$ had no resolution signs for their skin lesions and recruited for the same purpose as group (B) for the above purpose.

\section{IFN- $\gamma$ and NO levels}

Before pentostam therapy, the levels of IFN- $\gamma$ and NO in patients' sera were higher in group (A) than in group (B). Nonparametric Mann-Whitney test was used for comparative studies (Table 3). Statistically, the differences observed between the 2 groups were highly significant $(P=0.000,2$-tailed).

\section{DISCUSSION}

During this relatively-short study period, 90 patients with active leishmanial skin lesions were identified in the study's setting. At first glance, the absolute number of cases detected per one year seems relatively large, inconsistent with previous reports from the same setting [12]. Factors like the increasing urbanization close to the nearby endemic foci, the growing population's size and the frequent population's movement could be explanations. Moreover, the progress made in disease's diagnosis and the increase in population's awareness towards

Table 3. Serum concentration of interferon-gamma (IFN- $\gamma)$ and nitric oxide (NO) in healing and non-healing leishmanial groups before pentostan ${ }^{\circledR}$ treatment

\begin{tabular}{|c|c|c|c|c|c|c|c|c|c|}
\hline \multirow{3}{*}{$\begin{array}{l}\text { Cytokine } \\
\text { Percentile }\end{array}$} & \multicolumn{6}{|c|}{ Treatment groups } & \multicolumn{3}{|c|}{ Statistical test } \\
\hline & \multicolumn{3}{|c|}{ Healing } & \multicolumn{3}{|c|}{ Non-healing } & \multirow[t]{2}{*}{ Mann-Whitney U } & \multirow[t]{2}{*}{ Sig (2-tailed) } & \multirow[t]{2}{*}{$95 \% \mathrm{Cl}$} \\
\hline & Median & 25 & 75 & Median & 25 & 75 & & & \\
\hline IFN- $\gamma(\mathrm{pg} / \mathrm{ml})$ & $2,202.5$ & $2,135.6$ & $2,375.9$ & 194.3 & 158.4 & 291.8 & 8.000 & $0.000^{\star}$ & $0-030$ \\
\hline $\mathrm{NO}(\mu \mathrm{mol} / \mathrm{L})$ & 38.2 & 31.8 & 55.1 & 6.2 & 4.8 & 8.7 & 6.000 & $0.000^{\star}$ & $0-030$ \\
\hline
\end{tabular}

Healing group, patients displayed rapid clinical cure after pentostan ${ }^{\circledR}$ treatment $(n=34)$; Non-healing group, patients did not display clinical cure signs for pentostan ${ }^{\circledR}$ treatment $(n=13)$; Sig (2-tailed), 2-tailed $P$-value; ${ }^{*}$ Highly significant; $\mathrm{Cl}$, confidence interval. 
the value of early treatment may be additional explanations. Taken together, it was clear that CL in the study setting is more frequent than perceived in the literature and mandate further attention from the health authorities.

CL cases were reported all the year around, but most of the cases were reported in the winter, in agreement with previous Saudi studies $[13,14]$. Conversely, in a study, carried out in southeastern Tunisia, most of the cases were recorded in the summer [15]. The local climate and its effects on the host-vector activities could explain seasonality variations among different studies [16]. All CL lesions were confined to the skin with no mucosal tissue involvement or nodular dissemination noticed in all cases, consistent with previous studies $[17,18]$ and inconsistent with others $[19,20]$.

The patient's young age, male gender, rural residence, and frequent travel were proven risk factors for CL in the study's setting. Although no age was found immune to infection, patients below 20 years were the most susceptible age group. Identical observation has been displayed in an earlier report [21]. In contrast to our finding, patients aged 20-30 years have been described as a high - risk group, in one study [22] while older patients (40-60 years) were the most vulnerable group in another [18]. Regarding gender distribution, a definite male preponderance, with 3.5: 1 male to female ratio, was defined in our study. The same path has been widely perceived in other Saudi $[13,14]$ and non-Saudi endemic loci [23]. Inconsistent with our finding, an equal distribution of CL cases between males and females has been also reported in one study [24] and the female gender predominance has been reported in another [25]. Perhaps, the above striking differences among studies are related to the cultural difference, behavioral patterns and occupational activities of the studied populations.

Also in our study, the microscopic examination of stained smear prepared from lesion's scraping displayed sensitivity of $74 \%$, higher than that previously reported. Sensitivities of $42 \%$ $-70 \%$ have been reported in earlier studies $[23,25]$. All skin scraping samples that diagnosed as negatives by microscopy were proved positives for leishmanial DNA by one of the 2 PCR assays. The kDNA PCR was more sensitive than the OligoC-TesT, consistent with one study [26]. The high sensitivity of the kDNA PCR could be due to the high copy number of the selected gene, the highly conserved nature of the targeted DNA sequence targeted and the adopted semi-nested PCR format.

Furthermore, pentostam ${ }^{\circledR}$ with the 20 day-intramuscular therapeutic regimen was effective in treating $85 \%$ of cases. Low- er cure rates have been reported in endemic regions elsewhere in the country $[27,28]$. Factors like the therapeutic regimen, the causative leishmania species, the lesion's severity and duration, and the patient's immune and health status, all can explain the variations of the drug efficacy displayed among studies [29].

Before pentostam ${ }^{\circledR}$ treatment, highly significant levels of IFN- $\gamma$ and NO were exhibited in healing than non-healing patients groups, in agreement with an earlier study [30]. Conversely, Taheri et al. [31] have reported statistically non-significant difference regarding serum IFN- $\gamma$ between CL cases and a group of healthy individual enrolled in the study as controls. Despite this discrepancy, our finding opens 2 perspectives for IFN- $\gamma$ use as a biomarker capable to diagnose cases and predict responders from non-responders, and as an adjuvant medication to pentostam for treating resistant cases.

In fact, this study was not without limitations. Our results could be subjected to selection bias as the study's population was hospital-based, or exposed to recall bias, because some findings relied solely on the patients' memories. Due to cultural habits, the number of male and male participant were not adequately matched, thus, the sex distribution of CL could be also biased. Lastly, because of the study's short period, post-treatment follows up visits could not be delivered in a way that allows us to comment on treatment resistant and relapsed cases.

To conclude, $\mathrm{CL}$ is prevalent in Taif region and the registered number of cases is rising all the year around, especially in the winter. All CL cases, evaluated, are of a localized skin lesion with no mucosal tissue involvement or papulo-nodular dissemination. Young age, male gender, rural residence, travel to endemic foci, all were determined as risk factors. Most of cases presented with a single ulcerative lesion in the face, followed by the upper and lower limbs. Moreover, the kDNA PCR assay proved most sensitive diagnostic tool, followed by the OligoCTesT kit and microscopy. Pentostam ${ }^{\circledR}$ with the adopted regimen proved effective in treating $85 \%$ of cases, especially those IFN- $\gamma$ and NO levels in their sera before treatment initiation. We recommend more in-depth field and longitudinal studies in the near future to support our study's findings.

\section{ACKNOWLEDGMENTS}

This research was supported by a grant (Project No. 1-4374895) through the Research Support of Taif University, Saudi Arabia. The authors acknowledge the valuable assistance provided by Dr Ahmed M. Khalifa, for his help and support while 
doing the study's statistics.

\section{CONFLICT OF INTEREST}

All authors declare no conflict of interest.

\section{REFERENCES}

1. Reithinger R, Dujardin JC, Louzir H, Pirmez C, Alexander B, Brooker S. Cutaneous leishmaniasis. Lancet Infect Dis 2007; 7: 581-596.

2. Alvar J, Vélez ID, Bern C, Herrero M, Desjeux P, Cano J, Jannin J, den Boer M. Leishmaniasis worldwide and global estimates of its incidence. PLoS One 2012; 7: e35671.

3. Dowlati Y. Cutaneous leishmaniasis: clinical aspect. Clin Dermatol 1996; 14: 425-431.

4. von Stebut E. Immunology of cutaneous leishmaniasis: the role of mast cells, phagocytes and dendritic cells for protective immunity. Eur J Dermatol 2007; 17: 115-122.

5. Carneiro PP, Conceição J, Macedo M, Magalhães V, Carvalho $\mathrm{EM}$, Bacellar $\mathrm{O}$. The role of nitric oxide and reactive oxygen species in the killing of Leishmania braziliensis by monocytes from patients with cutaneous leishmaniasis. PLoS One 2016; 11: e0148084.

6. Vega-López F. Diagnosis of cutaneous leishmaniasis. Curr Opin Infect Dis 2003; 16: 97-101.

7. Reithinger R, Dujardin JC. Molecular diagnosis of leishmaniasis: current status and future applications. J Clin Microbiol 2007; 45: 21-25.

8. Copeland NK, Aronson NE. Leishmaniasis: treatment updates and clinical practice guidelines review. Curr Opin Infect Dis 2015; 28: 426-437.

9. Ponte-Sucre A, Gamarro F, Dujardin J, Barrett MP, López-Vélez R, García Hernández R, Pountain AW, Mwenechanya R, Papadopoulou B. Drug resistance and treatment failure in leishmaniasis: A 21st century challenge. PLoS Negl Trop Dis 2017; 11: e0006052.

10. Saab M, El Hage H, Charafeddine K, Habib RH, Khalifeh I. Diagnosis of cutaneous leishmaniasis: why punch when you can scrape? Am J Trop Med Hyg 2015; 92: 518-522.

11. Aransay AM, Scoulica E, Tselentis Y. Detection and identification of Leishmania DNA within naturally infected sand flies by seminested PCR on minicircle kinetoplastic DNA. Appl Environ Microbiol 2000; 66: 1933-1938.

12. Abuzaid AA, Abdoon AM, Aldahan MA, Alzahrani AG, Alhakeem RF, Asiri AM, Alzahrani MH, Memish ZA. Cutaneous leishmaniasis in Saudi Arabia: a comprehensive overview. Vector Borne Zoonotic Dis 2017; 17: 673-684.

13. Amin TT, Al-Mohammed HI, Kaliyadan F, Mohammed BS. Cutaneous leishmaniasis in Al Hassa, Saudi Arabia: epidemiological trends from 2000 to 2010. Asian Pac J Trop Med 2013; 6: 667672.
14. Haouas N, Amer O, Ishankyty A, Alazmi A, Ishankyty I. Profile and geographical distribution of reported cutaneous leishmaniasis cases in northwestern Saudi Arabia, from 2010 to 2013. Asian Pac J Trop Med 2015; 8: 287-291.

15. Bousslimi N, Aoun K, Ben-Abda I, Ben-Alaya-Bouafif N, Raouane $\mathrm{M}$, Bouratbine A. Epidemiologic and clinical features of cutaneous leishmaniasis in southeastern Tunisia. Am J Trop Med Hyg 2010; 83: 1034-1039.

16. Chaves LF, Pascual M. Climate cycles and forecasts of cutaneous leishmaniasis, a nonstationary vector-borne disease. PLoS Med 2006; 3: e295.

17. Zakai HA. Cutaneous leishmaniasis in Saudi Arabia: current status. J Adv Lab Res Biol 2014; 5: 29-34.

18. Al-Gindan Y, Abdul-Aziz O, Kubba R. Cutaneous leishmaniasis in Al-Hassa, Saudi Arabia. Int J Dermatol 1984; 23: 194-197.

19. Al-Gindan Y, Omer AH, A-Humaidan Y, Peters W, Evans DA. A case of mucocutaneous leishmaniasis in Saudi Arabia caused by Leishmania major and its response to treatment. Clin Exp Dermatol 1983; 8: 185-188.

20. Morsy TA, Khalil NM, Salama MM, Hamdi KN, al Shamrany YA, Abdalla KF. Mucosal leishmaniasis caused by Leishmania tropica in Saudi Arabia. J Egypt Soc Parasitol 1995; 25: 73-79.

21. Khan W, Zakai HA. Epidemiology, pathology and treatment of cutaneous leishmaniasis in Taif region of Saudi Arabia. Iran J Parasitol 2014; 9: 365-373.

22. Fendri AH, Beldjoudi W, Ahraou S, Djaballah M. Leishmaniasis in Constantine (Algeria): review of five years (2006-2010) at the University Hospital. Bull Soc Pathol Exot 2012; 105: 46-48 (in French).

23. Farahmand M, Nahrevanian H, Shirazi HA, Naeimi S, Farzanehnejad Z. An overview of a diagnostic and epidemiologic reappraisal of cutaneous leishmaniasis in Iran. Braz J Infect Dis 2011; 15: $17-21$.

24. Al-Tawfiq JA, AbuKhamsin A. Cutaneous leishmaniasis: a 46year study of the epidemiology and clinical features in Saudi Arabia (1956-2002). Int J Infect Dis 2004; 8: 244-250.

25. Rasti S, Ghorbanzadeh B, Kheirandish F, Mousavi SG, Pirozmand A, Hooshyar H, Abani B. Comparison of molecular, microscopic, and culture methods for diagnosis of cutaneous leishmaniasis. J Clin Lab Anal 2016; 30: 610-615.

26. Bensoussan E, Nasereddin A, Jonas F, Schnur LF, Jaffe CL. Comparison of PCR assays for diagnosis of cutaneous leishmaniasis. J Clin Microbiol 2006; 44: 1435-1439.

27. Franke ED, Wignall FS, Cruz ME, Rosales E, Tovar AA, Lucas CM, Llanos-Cuentas A, Berman JD. Efficacy and toxicity of sodium stibogluconate for mucosal leishmaniasis. Ann Intern Med 1990; 113: 934-940.

28. Wortmann G, Miller RS, Oster C, Jackson J, Aronson N. A randomized, double-blind study of the efficacy of a 10- or 20-day course of sodium stibogluconate for treatment of cutaneous leishmaniasis in United States military personnel. Clin Infect Dis 2002; 35: 261-267.

29. Decuypere S, Vanaerschot M, Brunker K, Imamura H, Müller S, 
Khanal B, Rijal S, Dujardin JC, Coombs GH. Molecular mechanisms of drug resistance in natural Leishmania populations vary with genetic background. PLoS Negl Trop Dis 2012; 6: e1514.

30. Kwieder M. Analysis of cellular immune response in cutaneous leishmaniasis Syrian patients. Int J PharmTech Res 2016; 8: 60-
65.

31. Taheri AR, Mashayekhi Goyonlo V, Nahidi Y, Moheghi N, Tavakkol Afshari J. Plasma levels of interlukin- 4 and interferon- $\gamma$ in patients with chronic or healed cutaneous leishmaniasis. Iran J Basic Med Sci 2014; 17: 216-219. 